\title{
Surface segregation phenomena in extended and nanoparticle surfaces of $\mathrm{Cu}$-Au alloys
}

\author{
Jonathan $\mathrm{Li}^{1}$, Guofeng Wang ${ }^{2}$ and Guangwen $\mathrm{Zhou}^{3 *}$ \\ ${ }^{1}$ Department of Physics, Applied Physics and Astronomy \& Materials Science and Engineering Program, State \\ University of New York, Binghamton, NY 13902 \\ ${ }^{2}$ Department of Mechanical Engineering and Materials Science, \\ University of Pittsburgh, Pittsburgh, PA 15261 \\ ${ }^{3}$ Department of Mechanical Engineering \& Materials Science and Engineering Program, State University of New \\ York, Binghamton, NY 13902
}

\begin{abstract}
Using density functional theory (DFT) and Monte-Carlo (MC) simulations, we studied the surface segregation phenomena of $\mathrm{Au}$ atoms in the extended and nanoparticle surfaces of $\mathrm{Cu}-\mathrm{Au}$ alloys. Our $\mathrm{MC}$ simulations predicted significant $\mathrm{Au}$ enrichment in the outermost layer of (111) and (100) extended surfaces, and $\mathrm{Au}$ enrichment in the two outermost layers of (110) extended surfaces. The equilibrium $\mathrm{Cu}$-Au nanoparticles were predicted to develop into an Au-enriched shell structure, where Au atoms preferably segregate to the (100) facets while $\mathrm{Cu}$ atoms are mainly located on the (111) facet of the nanoparticles. Our simulation predictions agree with experimental measurements.
\end{abstract}

*To whom correspondence should be addressed:guw8@pitt.edu (G. Wang); gzhou@,binghamton.edu (G. Zhou) 


\section{INTRODUCTION}

Copper $(\mathrm{Cu})$ catalysts have been studied extensively for their uses in catalysis. Some of the chemical reactions catalyzed by $\mathrm{Cu}$ are hydrogenation, $\mathrm{CO}_{2}$ reduction and $\mathrm{CO}$ oxidation [1,2]. However, $\mathrm{Cu}$ is easily oxidized, making the metal unstable which compromises the catalytic activity [3,4]. One solution to this oxidation problem is to alloy $\mathrm{Cu}$ with a stabilizing metal, such as $\mathrm{Au}$, which is resistant to corrosion and oxidation. Bimetallic $\mathrm{Cu}-\mathrm{Au}$ alloys have also been known to improve catalytic properties over their single metal counterparts such as low-temperature $\mathrm{CO}$ oxidation $[5,6]$ and selective hydrogenation $[7,8]$. Bimetallic catalysts offer a great advantage by offering a way to fine-tune the catalytic properties of metals $[9,10]$. Catalytic activities of bimetallic alloys are mainly determined by their surface composition. It is desirable to increase the Au surface concentration, while keeping the cost of the catalysts low. This can be achieved by taking advantage of the surface segregation, resulting in a greater $\mathrm{Au}$ surface concentration relative to the bulk concentration. By predicting the surface composition of $\mathrm{Cu}$-Au alloys, we can design and synthesize catalysts with desirable catalytic properties.

Surface segregation phenomenon in alloy materials causes a difference in surface chemical composition from the bulk composition $[11,12]$. This process can alter many physical and chemical properties such as adsorption, wetting, oxidation, corrosion, crystal growth and catalysis [13,14]. There have been multiple experimental studies regarding surface segregation in copper-gold alloys. Experimental methods used for determination of the surface layer composition profile of crystalline samples include Auger electron spectroscopy - AES [15-17] low-energy ion scattering - LEIS [18-20], medium-energy ion scattering - MEIS [21], low-energy electron diffraction - LEED [20], X-ray crystal truncation rod (CTR) diffraction [22,23]. All of these studies have showed that $\mathrm{Au}$ would enrich the surface. For example, it was found that the (111) surface of $\mathrm{Au}$ concentration of the $\mathrm{Cu}-\mathrm{Au}$ alloy could reach $40 \%$ at $900 \mathrm{~K}$ [16] and 51\% at $573 \mathrm{~K}$ [17] with a bulk Au concentration of $20 \%$, and $25 \%$ at $386 \mathrm{~K}$ [18] with a bulk Au concentration of $10 \%$. The (110) surface Au concentration was found to be $35 \%$ at $660 \mathrm{~K}$ [20] with a bulk Au concentration of $25 \%, 30 \%$ at $386 \mathrm{~K}$ [20] with a bulk Au concentration of $10 \%$ and about $27 \%$ at $386 \mathrm{~K}^{18}$ with a bulk Au concentration of $10 \%$. With a bulk Au concentration of $25 \%$, the (100) surface Au concentration of the $\mathrm{Cu}-\mathrm{Au}$ alloy was $41 \%$ at $1000 \mathrm{~K}$ [19], 45\% at $890 \mathrm{~K}[22,23]$ and $36 \%$ at $990 \mathrm{~K}$ [15]. Moreover, the surface segregation process in $\mathrm{Cu}-\mathrm{Au}$ alloys has been 
studied using different theoretical methods [24-30]. Most of the theoretical studies do not report the surface composition of the alloys.

The theoretical studies on $\mathrm{Cu}-\mathrm{Au}$ surface enrichment have been focused mainly on the (100) surface, while there are a few on the (111) surface, and results for (110) are scarce. Although some of these calculations accurately predict the surface composition for the specific surface being studied, the potentials have not been thoroughly evaluated by taking other surfaces into account and have other limitations, as described below. Fitting the potential parameter based on one surface orientation is a big disadvantage as the predictions may only be accurate for that specific surface but not be for other surfaces. There have not been many surface composition predictions of $\mathrm{Cu}-\mathrm{Au}$ alloys involving multiple surfaces: Hayoun et al. [29] calculated the surface composition of $\mathrm{Cu}_{3} \mathrm{Au}(100)$ and (111), and Hou et al. [30] studied the surface composition of the (111), (100) and (110) surfaces of $\mathrm{Cu}_{3} \mathrm{Au}$. Both of these studies have limitations that should be considered. Hayoun et al. [29] fitted the parameters of their potentials to various experimental bulk quantities. They reported that surface quantities, mainly the composition of the outermost layer and the existence of buckling, are sensitive to the details of the potential. This may be due to the fact that they developed their potential based on experimental bulk data without considering surface properties. The study also only made predictions of (100) and (111) surfaces, but not the (110) surface, so there may be some lacking evidence of how accurately the potential describes the (110) surface. Hou et al. [30] also developed their potential based on experimental bulk quantities. Again, since the model potential was fitted to bulk properties of the $\mathrm{Cu}_{3} \mathrm{Au}$ alloy, it may be unreliable because surface predictions can be sensitive to the potential. Furthermore, many of the theoretical studies do not publish specific potential parameter details to be added to a library of developed potentials. There has also been more focus on controlling surface composition and structures of alloy nanostructures, so it is desirable to simulate the surface segregation phenomena in both extended surfaces and nanostructures, such as nanoparticles.

To address all of these limitations, we have developed the parameters of the modified embedded-atom method (MEAM) potentials for $\mathrm{Cu}-\mathrm{Au}$ alloys and performed the Monte Carlo (MC) simulations of the equilibrium surface composition of the extended surfaces of $\mathrm{Cu}-\mathrm{Au}$ alloys taking into account the three lowindex surfaces [(111), (100) and (110)]. The results are compared with experimental measurements. We have developed the potential parameters to fit both bulk and surface properties, calculated by density functional theory 
(DFT). In addition, we simulated the surface segregation process in nanoparticles and report the composition in different regions of nanoparticles.

\section{COMPUTATION METHODS}

\section{A. DFT calculations}

The DFT [31,32] calculations were performed using the Vienna Ab Initio Simulation Package (VASP) [33] with the projector augmented wave approach [34,35]. We used the DFT method to determine bulk properties of the $\mathrm{Cu}-\mathrm{Au}$ alloys, as well as the various surface segregation energies in the $\mathrm{Cu}-\mathrm{Au}$ - alloys. The generalized gradient approximation (GGA) with the PW91 functional was used for evaluating the exchange-correlation energy [36,37]. We used a plane-wave cutoff energy of $600 \mathrm{eV}$ in all the calculations. The Brillouin-zone integration is performed using $(16 \times 16 \times 16)$ Monkhorst-Pack k-point meshes for the bulk unit cell calculations, and a $(5 \times 5 \times 1)$ k-point mesh was used for our surface slab calculations. All of the atoms in our models were free to relax until the Hellman-Feyman forces were minimized and each force component acting on the atoms was lower than $0.01 \mathrm{eV} / \AA$.

\section{B. The MC method}

In this work, we used the MC method that was used previously used by Duan and Wang in the study of surface segregation of Pt-Pd alloys [38]. At each simulation step, we attempted to exchange the positions of two randomly chosen atoms from an initial assumed configuration of the $\mathrm{Cu}-\mathrm{Au}$ alloys. At a given temperature, the probability $P_{X Y}$ of a configuration transformation (from $\mathrm{X}$ to $\mathrm{Y}$ ) is determined by the Boltzmann factor (distribution function) of the energy change $\left(\Delta E=E_{Y}-E_{X}\right)$ of a system,

$$
P_{X Y}=\exp \left[\frac{-\Delta E}{k_{B} T}\right]
$$

where $k_{B}$ is the Boltzmann constant and $T$ is the temperature. In our $\mathrm{MC}$ algorithm, the new configuration was kept if $P_{X Y} \geq 1$ (energy decreases); while when $P_{X Y}<1$ (energy increases), the new configuration was kept only if $\mathrm{P}_{\mathrm{XY}}$ was larger than a computer-generated random number, which ranged from 0 to 1 . We repeated this operation millions of times to yield the thermodynamic equilibrium configurations of the modeled $\mathrm{Cu}-\mathrm{Au}$ surfaces. 
The energy change $\Delta E$ [in Eq. (1)] was evaluated using our developed MEAM atomic interaction potentials. A screening procedure was adopted in defining the nearest neighbors for an atom since only the nearest neighboring interactions were considered in our current MEAM. Detailed information regarding the MEAM potentials for alloy systems can be found in Refs. [39-45].

\section{RESULTS AND DISCUSSION}

\section{A. DFT study of surface segregation in low-index surfaces of $\mathrm{Cu}$-Au alloys}

The segregating tendency of the component atoms to the alloy surfaces can be gauged by their surface segregation energy. The surface segregation energy in extended $\mathrm{Cu}-\mathrm{Au}$ surfaces is computed as the energy difference between the total energy of the systems with a segregating species atom in the surface layer and in the bulk. In this work, negative surface segregation energy indicates that it is energetically favorable for the segregating atom to segregate to the surface. Using the DFT method, we have calculated the surface segregation energy in the dilute limit as well as in an ordered alloy $\left(\mathrm{L1}_{2} \mathrm{Cu}_{3} \mathrm{Au}\right)$ of the $\mathrm{Cu}$-Au alloys. The three low-index surfaces [(111), (100), (110)] of the Cu-Au alloys were modeled with surface slabs in periodic super cells.

In the dilute alloy case, we modeled the $\mathrm{Cu}$ - $\mathrm{Au}$ surface as a $\mathrm{Cu}$ surface slab containing one $\mathrm{Au}$ atom. In all these surface models, we included seven atomic layers (4 atoms at each layer) and a $10 \AA$ thick vacuum region perpendicular to the surfaces. Our DFT results in Table 1 indicate that $\mathrm{Au}$ atoms in the bulk of a $\mathrm{Cu}$ slab have a strong tendency to segregate to the upper most layer in (111), (100) and (110) surfaces because of the decrease in energy that we found from the surface segregation energy calculations. For comparison, we also listed in Table 1 the previous predictions for the segregation energy of an $\mathrm{Au}$ atom to the $\mathrm{Cu}$ surface from the DFT calculations with local density approximation (LDA) [46,47]. The discrepancy in the quantitative values between our and previous studies is probably due to the different computational surface models employed. We used a $2 \times 2$ surface unit cell for our present study whereas the previous DFT-LDA study used a large $6 \times 6$ surface unit cell [47]. Nonetheless, it could be seen that our predicted surface segregation energies follow the same general trend (preference of Au surface segregation) as those DFT-LDA data [46, 47]. Moreover, Wang and Johnson used the DFT-GGA method to calculate the segregation energy of an Au atom to the surface (specifically, the edge site between (111) and (100) facets) of an $\mathrm{Au}-\mathrm{Cu}$ particle having $54 \mathrm{Cu}$ atoms and one $\mathrm{Au}$ 
atom [48]. They found that $\mathrm{Au}$ would prefer to stay on the surface of the particle, in agreement with our results for extended surfaces.

In its equilibrium form, the $\mathrm{Cu}_{3} \mathrm{Au}$ alloy adopts an $\mathrm{L}_{2}$ crystal structure in which one $\mathrm{Au}$ atom lies at the corner of a cubic unit cell and three $\mathrm{Cu}$ atoms lie at the face centers of a face-centered cubic lattice. The lattice parameter of the $\mathrm{Cu}_{3} \mathrm{Au}\left(\mathrm{L1}_{2}\right)$ crystal was predicted from our DFT calculations to be $3.791 \AA$, which is about $1.09 \%$ larger than the experimental data of $3.75 \AA$ [49]. In the ordered alloy case of the $\mathrm{Cu}_{3} \mathrm{Au}$ surface slab, we have calculated the surface segregation energies of various configurations as shown in Fig. 1. In all of our alloy models, the cells consisted of 8 atomic layers and a $10 \AA$ thick vacuum region in the direction normal to the surfaces. An 8 layer slab is used in the ordered alloy case to allow the atoms to enrich to the distinct top and bottom surfaces. Our DFT results in Table 2 show that all the three surfaces prefer to have Au enrichment to the surface. More specifically, for the (111) and (100) surface, there is a tendency for Au atoms to segregate to the surface layer from the second layer, but it is not energetically favorable for the (111) or (100) surface to be covered greater than $50 \% \mathrm{Au}$. The results for the (110) surface show that $\mathrm{Au}$ atoms prefer to enrich to both the second and first layer, and it is favorable for the surface to be covered greater than $50 \% \mathrm{Au}$, unlike the case for (111) and (100).

\section{B. Developing Cu-Au MEAM potential}

We have calculated the lattice parameters of $\mathrm{Cu}-\mathrm{Au}$ alloys and the segregation energies of various cases involving $\mathrm{Cu}, \mathrm{Au}$ and $\mathrm{Cu}_{3} \mathrm{Au}$ as discussed above. Furthermore, we developed the parameters of MEAM potentials to reproduce the 18 quantitative results obtained from these DFT calculations for both lattice parameters and surface segregation energies, which are the values given in Tables 1,2 and 3 . All the configurations used for calculating the surface segregation energy are shown in Fig. 1. We report the thusattained parameters for the $\mathrm{Cu}-\mathrm{Au}$ MEAM potentials in Table 4 and the angular screening parameters for the potential in Table 5 .

In Table 6, we list the calculated surface energies for the three low-index surfaces of the pure $\mathrm{Cu}$ and $\mathrm{Au}$ crystals. Although the calculated surface energies using MEAM are lower than the previous DFT calculations as well as experimental measurements, our MEAM calculated surface energies for $\mathrm{Cu}$ and $\mathrm{Au}$ are in good 
agreement with previous results calculated by Baskes [41]. It is a known fact that most atomic potential models predict lower surface energies than experimental data $[41,42]$. In this study, we found that the $\mathrm{Au} / \mathrm{Cu}$ surface energy ratio calculated by MEAM and DFT for the (111), (100) and (110) surfaces are 0.614 and 0.657, 0.626 and 0.751 , and 0.6037 and 0.763 , respectively. Hence, the relative difference in surface energy, which could be a more important factor influencing surface segregation, is not as pronounced as the absolute difference between the MEAM and DFT methods. More importantly, both DFT and MEAM calculations predict a lower surface energy for pure $\mathrm{Au}$ in all the three low-index surfaces, favoring $\mathrm{Au}$ segregation to the surface of the $\mathrm{Cu}-\mathrm{Au}$ alloys in order to lower the overall surface energy.

We fitted the MEAM cross-potentials between $\mathrm{Cu}$ and $\mathrm{Au}$ with the DFT results (described in Section III A.) about the lattice parameter of $\mathrm{Cu}_{3} \mathrm{Au}$ crystal ( $\mathrm{L1}_{2}$ crystal structure), $\mathrm{CuAu}$ crystal $\left(\mathrm{L}_{0}\right.$ crystal structure) and $\mathrm{CuAu}_{3}$ structure $\left(\mathrm{Ll}_{2}\right.$ crystal structure). Shown in Table 3 are lattice parameter, calculated from our developed MEAM potentials, of the $\mathrm{Cu}_{3} \mathrm{Au}$ and $\mathrm{CuAu}_{3}$ crystal agrees well with DFT calculations and experimental results, but the lattice parameters for the CuAu crystal do not quantitatively agree. This may be due to the fact that we are focused on reproducing surface segregation energies for the cubic phase rather than the tetragonal phase. In Table 1, we show the segregation energies for an Au atom in the (111), (100) and (110) surfaces of Cu crystals using DFT compared with calculations from our MEAM potentials. We fitted the MEAM potentials for many structures in both Tables 1 and 2, however, we cannot reproduce every result exactly and have to make some compromises. Although the results for segregation of the $\mathrm{Au}$ atom in the $\mathrm{Cu}$ slabs differ quantitatively, they agree qualitatively (having the same positive or negative sign). Both DFT and MEAM calculations predict that the Au atoms would segregate to the surfaces of the $\mathrm{Cu}$ single crystals in (111), (100) and (110) surfaces.

We have also performed surface segregation calculations of various configurations of the $\mathrm{Cu}_{3} \mathrm{Au}$ ordered alloy with Au segregation. Shown in Fig.1 are the different configurations of the Au segregation. We used an even number of layers to allow Au surface segregation to occur on both the top and bottom of the slab to represent different surface compositions. Table 2 shows the surface segregation energies corresponding to different configurations of the $\mathrm{Cu}_{3} \mathrm{Au}$ alloy. In the $\mathrm{Cu}_{3} \mathrm{Au}$ ordered alloy, the DFT calculations reveal that there is a tendency for the Au atoms to segregate to the surface in all the three low index surfaces. However, two of our MEAM calculated segregation energies disagree with the DFT results, J-K and J-M for the (110) surface. The 
DFT calculations suggest that it is energetically favorable for the two outermost layers of the (110) surfaces to be enriched with $\mathrm{Au}$, but the two MEAM calculations do not favor a $75 \% \mathrm{Au}$ outermost layer or $25 \% \mathrm{Au}$ in both the 1st and 2nd outermost layers.

\section{Simulation of surface segregation in extended surfaces of $\mathrm{Cu}-\mathrm{Au}$ alloys}

Due to the high computational costs of DFT, quantitative predictions of surface composition profiles cannot be accomplished. To overcome this limitation, we combine $\mathrm{MC}$ simulations with our developed $\mathrm{Cu}-\mathrm{Au}$ MEAM potentials to quantitatively predict the equilibrium surface composition. First, we set the MC simulation annealing temperature at $900 \mathrm{~K}$ to match the common sample temperatures used in experiments for the (111), (100) and (110) surfaces. We performed the MC simulations for the three-dimensional periodic cubic simulation cells containing 256 randomly distributed $\mathrm{Cu}$ and $\mathrm{Au}$ atoms at $900 \mathrm{~K}$ to determine the lattice constants for the $\mathrm{Cu}-\mathrm{Au}$ bulk alloy. We can use a random distribution of $\mathrm{Cu}$ and $\mathrm{Au}$ atoms because our $\mathrm{Cu}-\mathrm{Au}$ alloy is in a disordered phase at $900 \mathrm{~K}$. The lattice constant of the $\mathrm{Cu}-\mathrm{Au}$ alloy with the given $\mathrm{Au}$ concentration was determined from the dimensions of the simulation cell that led to zero average pressure from the MC simulations.

We carried out the $\mathrm{MC}$ simulations to quantitatively predict the Au concentrations in the outermost surface layers of the (111), (100) and (110) surface of the $\mathrm{Cu}$-Au alloys. We first modeled these three low-index surfaces using surface slab cells, which have periodic boundaries in the two directions parallel to the surface and a free boundary in the direction normal to the surface, which makes two surfaces in each slab simulation cell. The dimensions of these surface slab cells were determined from the lattice constants of the bulk $\mathrm{Cu}-\mathrm{Au}$ alloy with the same composition. Different numbers of atomic layers were used to make the surface slabs have similar thicknesses of around $30 \AA$. The (111) surface slab models contain 15 layers with 48 atoms in each layer, the (100) surface slab models contain 17 layers with 32 atoms in each layer, and the (110) surface slab models contain 23 layers with 48 atoms in each. Starting from these initial structures, we conducted $2 \times 10^{6} \mathrm{MC}$ steps at $900 \mathrm{~K}$. Due to the finiteness of the slab model used in the simulation, the Au composition in the bulk region (the middle five layers of the slab model) could be altered after the MC simulation. To correct this, we ran a series of MC simulations and adjusted the overall bulk composition until the correct bulk composition of $25 \%$ at the 
center of the simulation cells was achieved. In Table 7, we reported our theoretical predictions of Au segregation profiles in the (110), (100) and (111) surfaces of $\mathrm{Cu}-\mathrm{Au}$ alloys from our MC simulations.

In addition, we compare our predictions with experimental and theoretical values from the literature. In this study, we predicted that the Au concentrations in the first and second layer of the $\mathrm{Cu}-\mathrm{Au}$ surfaces were $40.2 \%$ and $14.3 \%$ (un-relaxed), $51.4 \%$ and $13.9 \%$ (relaxed) in the (111) surface with $20 \%$ bulk Au concentration, $53.6 \%$ and $14.6 \%$ (un-relaxed), $59.7 \%$ and $12.8 \%$ (relaxed) in the (100) surface with $25 \%$ bulk Au concentration, $50.8 \%$ and $41.8 \%$ (un-relaxed), $54.2 \%$ and $39.8 \%$ (relaxed) in the (110) surface with $25 \%$ bulk Au concentration. As shown in Table 7, our predictions for Au concentrations in the first two layers of the $\mathrm{Cu}-\mathrm{Au}$ (111) surface agree very well with experimental $[16,17]$ as well as theoretical results $[29,30]$. Experimental and theoretical results for the (100) surface are the most abundant. The first layer of the (100) surface in our predictions is slightly more enriched with Au than the experimental results, but the second layer is depleted of Au, which is consistent with the experimental $[15,19,22,23]$ and theoretical results $[25,27,29,30]$. Both the (111) and (100) surfaces were predicted to have $\mathrm{Au}$ enrichment to the first layer while Au depletion in the second layer. In comparison, our simulation predicted that Au would enrich both the first and second outermost layers in the (110) surface, possibly due to the openness of the surface structure which exposes the atoms in the second layer. Compared to the experimental report, which used two different annealing temperatures of less than $400 \mathrm{~K}$ and $660 \mathrm{~K}[20]$ to find the (110) surface compositions of the alloy, our prediction reveals greater Au segregation to both the first and second outermost layers in the (110) surface, while previous theoretical calculations predicted a surface composition that was between our prediction and the experimental result [30]. Although the annealing temperature of the experiment differs from that of our simulations $(900 \mathrm{~K})$, the results are still consistent in the fact that there is $\mathrm{Au}$ enrichment in the first and second layers.

Our results in Table 7 show that the surface relaxation could lead to as high as 11.2 at. \% of Au concentration difference in the outermost layer of the (111) surface as compared to the unrelaxed model. In contrast, the surface relaxation leads to a modest 5.6 at. $\%$ of Au concentration difference in the outermost layer of the (110) surface as compared to the unrelaxed model. These results indicate that surface relaxation indeed affects the extent of $\mathrm{Au}$ surface segregation in the $\mathrm{Cu}-\mathrm{Au}$ alloys, in which $\mathrm{Au}$ 
atoms have a substantially larger radius than $\mathrm{Cu}$ atom. Moreover, our results suggest that the surface relaxation has more pronounced effect on the surface segregation in the closely packed (111) $\mathrm{Cu}-\mathrm{Au}$ surface than in the more-open (110) $\mathrm{Cu}$-Au surface. The effect of surface relaxation on the predicted surface segregation profile has been extensively examined in a previous study for Pt-Ni alloys [53]. Quite similar to the $\mathrm{Cu}-\mathrm{Au}$ system, Pt atoms have a much larger size than $\mathrm{Ni}$ atoms in the Pt-Ni alloy systems. As shown here, the same conclusion (i.e., surface relaxation affects the absolute values of surface composition profiles but does not change the general trend of surface segregation) is applicable to the $\mathrm{Cu}-\mathrm{Au}$ system. More detailed discussion about the effect of surface relaxation on the predicted surface segregation profile could be found in the previous study on the Pt-Ni alloys [53].

\section{Simulation of surface segregation in the nanoparticle surfaces of $\mathrm{Cu}-\mathrm{Au}$ alloys}

We have performed MC simulations to obtain the equilibrium Au concentrations in the surface of cubooctohedral $\mathrm{Cu}_{85} \mathrm{Au}_{15}, \mathrm{Cu}_{80} \mathrm{Au}_{20}$ and $\mathrm{Cu}_{75} \mathrm{Au}_{25}$ nanoparticles. In this work, we modeled four different sized cubooctahedral nanoparticles which contain 586, 1289, 2406 and 4033 atoms for each nanoparticle of different compositions. The $\mathrm{Cu}$ and $\mathrm{Au}$ atoms are randomly distributed in the initial nanoparticle structures. After carrying out $10 \times 10^{6} \mathrm{MC}$ simulation steps at temperatures of $T=500 \mathrm{~K}$, and sampling the Au concentrations in the surface, core and different surface sites every 1000 steps in the last $5 \times 10^{6}$ steps.

The snapshots of the equilibrium $\mathrm{Cu}-\mathrm{Au}$ nanoparticles are shown in Fig. 2. The edges of the nanoparticles have rounded up, due to the increased inward relaxation of the atoms at the low-coordination sites (edges and vertexes) compared to the atoms at the facet sites, to lower the total energy. The surface is also enriched with $\mathrm{Au}$ atoms. The $\mathrm{Au}$ atoms (yellow), mostly appear at the (100) facets in the equilibrium nanoparticle surfaces. It can also be seen from the cross sectional view that the core of the nanoparticles has been depleted of $\mathrm{Au}$ atoms and enriched with $\mathrm{Cu}$ atoms (blue).

Fig. 3 shows the plots of the calculated average Au concentrations in the shell (outermost layer), core (beneath the shell), (111) and (100) facets of the equilibrium $\mathrm{Cu}-\mathrm{Au}$ nanoparticles as a function of the nanoparticle diameters. The cubo-octohedral shape assumes the fcc lattice and is a truncated octahedron, which 
exhibits six (100) facets and eight (111) facets. Our results in Figs. 3(a, c, e) indicate that the Au concentrations in the shell were about $15-30 \%$ higher while the Au concentration in the core were about $10-25 \%$ lower, compared to the overall composition of the nanoparticles. Therefore, we predicted that the equilibrium $\mathrm{Cu}-\mathrm{Au}$ nanoparticle would have an Au-enriched shell and a Cu-enriched core. Our results in Figs. 3(b, d, f) show that the $\mathrm{Au}$ concentrations at the (111) and (100) facets of the equilibrium $\mathrm{Cu}-\mathrm{Au}$ nanoparticle surfaces differed. For all of the simulations of the $\mathrm{Cu}-\mathrm{Au}$ nanoparticles, the $\mathrm{Au}$ concentrations at the (100) facets were found to be slightly higher than those at the (111) facets. This is consistent with our calculations that Au segregates to the (100) extended surface more strongly than the (111) extended surface.

Our results in Fig. 3 also reveal that the size of the nanoparticles affected the surface segregation phenomena in the $\mathrm{Cu}-\mathrm{Au}$ nanoparticles. As seen from Figs. 3(a, c, e), both the shell and core become more enriched with $\mathrm{Au}$ as the nanoparticle's diameter increases, revealing that the smaller sized nanoparticles inhibit $\mathrm{Au}$ enrichment to the surface. As the particle size increases, the number of Au atoms grows faster than the surface area because of the decrease in surface-volume ratio as the nanoparticle size increases. We observed in Figs. 3(b, d, f) that the Au concentration at the (111) facets increases with increasing nanoparticle size for every $\mathrm{Au}$ composition and the Au concentration at the (100) facets increases with increasing nanoparticle size for $15 \%$ and $20 \%$ Au concentration. There is a very slight decrease in Au concentration with increasing nanoparticle size for the (100) facets at 25\% overall Au concentration, as seen in Fig. 3(f). Although the trend is decreasing, the $\mathrm{Au}$ concentration at the (100) facets does decrease and then increase alternately. Since the (100) facets are already highly saturated with Au atoms at a small nanoparticle diameter, the fluctuations may indicate deviations from the average maximum saturation at the (100) facets. Therefore, as the number of Au atoms grow with the increasing nanoparticle size, those Au atoms prefer to segregate to the (111) facets, thus only increasing the Au concentration at the (111) facets. The Au concentration at both (100) and (111) facets change more dramatically with increasing nanoparticle size at the lower overall Au composition (15\%) of the nanoparticle and changes less dramatically with increasing nanoparticle size as the overall Au composition increases. 


\section{CONCLUSION}

We have studied surface segregation in the low index extended surfaces of $\mathrm{Cu}-\mathrm{Au}$ alloys using DFT and MC simulations based on MEAM potentials. Our DFT results reveal that Au segregates to the outermost layer for all the three low index extended surfaces [(111), (100) and (110)]. Au also tends to segregate to the second outermost layer in the (110) surface. We then developed a set of parameters for the MEAM potential for the $\mathrm{Cu}$ Au alloys based on the DFT calculations, and then performed MC simulations employing the MEAM potentials. The MC simulations predict that $\mathrm{Au}$ atoms segregate to the outermost layer of the extended surfaces, and also to the second outermost layer of the (110) surface. We also predicted from our MC simulations that the equilibrium $\mathrm{Cu}-\mathrm{Au}$ nanoparticle would have an $\mathrm{Au}$-enriched shell and a $\mathrm{Cu}$-enriched core. The $\mathrm{Au}$ atoms prefer to segregate to the (100) facet, while the $\mathrm{Cu}$ atoms are mainly located on the (111) facet of the nanoparticles. The MC simulations based on MEAM potentials quantitatively predict the surface composition of various $\mathrm{Cu}-\mathrm{Au}$ alloys, and our predictions agree well with experimental measurements on many points.

\section{ACKNOWLEDGMENTS}

This work was supported by the U.S. Department of Energy, Office of Basic Energy Sciences, Division of Materials Sciences and Engineering under Award No. DE-SC0001135. G.F. Wang would like to acknowledge the research grant (Grant No. DMR-1410597) from the National Science Foundation. This work used the computational resources from the Extreme Science and Engineering Discovery Environment (XSEDE), which is supported by National Science Foundation grant number OCI-1053575. 


\section{References}

[1] H. Iwai, T. Umeki, M. Yokomatsu and C. Egawa, Surf. Sci. 602, 2541 (2008).

[2] R. Pérez-Hernándeza, G. Mondragón Galiciaa, D. Mendoza Anayaa, J. Palaciosa, C. Angeles-Chavezb and J. Arenas-Alatorrec, Int. J. Hydrogen Energy. 33, 4569 (2008).

[3] Y. Hori, Modern Aspects of Electrochemistry, vol. 42, (Springer, New York, 2008).

[4] J. J. Kim and J. K. W. Frese, J. Electrochem. Soc. 245, 223 (1988).

[5] A.S.K. Hashmi, G J. Hutchings, Angew. Chem. Int. Ed. 118, 8064 (2006).

[6] T.S. Mozer, D.A. Dziuba, C.T.P. Vieira and F.B. Passos, J. Power Sources. 187, 209 (2009).

[7] S. Song, R. Liu, Y. Zhang, J. Feng, D. Liu, Y. Xing, F. Zhao and H. Zhang, Chem. Eur. J. 16, 6251 (2010).

[8] A. Yin, C. Wen, W. L. Dai and K.N. Fan, J. Mater. Chem. 21, 8997 (2011).

[9] C.L. Bracey, P.R. Ellis and G.J. Hutchings, Chem. Soc. Rev. 38, 2231 (2009).

[10] J.G. Chen, C.A. Menning and M.B. Zellner, Surf. Sci. Rep. 63, 201 (2008).

[11] J. A. Rodriguez, Surf. Sci. Rep. 24, 223 (1996).

[12] M. Polak and L. Rubinovich, Surf. Sci. Rep. 38, 127 (2000).

[13] P.A. Dowben and W.A. Miller, Surface Segregation Phenomena (CRC, Boca Raton, FL, 1990).

[14] G. Wang, M.A. van Hove, P.N. Ross and M.I. Baskes, Prog. Surf. Sci. 79, 28 (2005).

[15] S. Mróz, Vac. 79, 241 (2005).

[16] S. Mróz and A. Krupski, Vac. 60, 307 (2001)

[17] J.M. McDavid and S.C. Fain. Jr, Surf. Sci. 52, 161 (1975).

[18] M.J. Sparnaay and G.E. Thomas, Surf. Sci. 135, 184 (1983).

[19] T.M. Buck, G.H. Wheatley and L. Marchut, Phys. Rev. Lett. 51, 43 (1983).

[20] E.G. McRae, T.M. Buck, R.A. Malic, W.E. Wallace and J.M. Sanchez, Surf. Sci. Lett. 238, L481 (1990)

[21] D.H. Oh, H.J. Kang, K.H. Chae, C.N. Whang, B.V. King, D.J. O'Connor, and D.W. Moon, Surf. Sci. 477, L289 (2001).

[22] H. Reichert, P. J. Eng, H. Dosch and J.K. Robinson, Phys. Rev. Lett. 74, 2006 (1995).

[23] H. Reichert and H. Dosch, Surf. Sci. 345, 27 (1996).

[24] W.K. Han, J. Korean. Phys. Soc. 58, 44 (2011). 
[25] K.R. Mecke and S. Dietrich, Phys. Rev. B. 52, 2107 (1995).

[26] J.M. Sanchez and J. L. Moran-Lopez, Surf. Sci. 157, L297 (1985)

[27] M.A. Hoffman and P. Wynblatt, Surf. Sci. 236, 369 (1990).

[28] S.M. Foiles, Surf. Sci. 191, 329 (1987).

[29] M. Hayoun, V. Pontikis and C. Winter, Surf. Sci. 398, 125 (1998).

[30] M. Hou, M. El Azzaoui, Surf. Sci. 380, 210 (1997)

[31] P. Hohenberg and W. Kohn, Phys. Rev. 136, B864 (1964).

[32] W. Kohn and L. Sham, Phys. Rev. A 140, 1113 (1965).

[33] G. Kresse and J. Hafner, Phys. Rev. B 54, 11169 (1996).

[34] P.E. Blöchl, Phys. Rev. B 50, 17953 (1994).

[35] R.O. Jones and O. Gunnarsson, Rev. Mod. Phys. 61, 689 (1989).

[36] J.P. Perdew and Y. Wang, Phys. Rev. B 33, 8800 (1986).

[37] J.P. Perdew, J.A. Chevary, S.H. Vosko, K.A. Jackson, M.R. Pederson, D.J. Singh and C. Fiolhais, Phys. Rev. B 46, 6671 (1992).

[38] Z. Duan and G. Wang, J. Phys.: Condens. Matter 23. 475301 (2011).

[39] M.S. Daw and M.I. Baskes, Phys. Rev. Lett. 50, 1285 (1983).

[40] M.S. Daw and M.I. Baskes, Phys. Rev. B 29, 6443 (1984).

[41] M.I. Baskes, Phys. Rev. B 46, 2727 (1992).

[42] M.I. Baskes and R.A. Johnson, Modell. Simul. Mater. Sci. Eng. 2, 147 (1994).

[43] G. Wang, M.A. van Hove, P.N. Ross and M.I. Baskes, J. Chem. Phys. 121, 5410 (2004).

[44] M.I. Baskes, Mater. Sci. Eng., A 261, 165, (1999).

[45] M.I. Baskes, Mater. Chem. Phys. 50, 152 (1997).

[46] A.V. Ruban, H.L. Skriver, and J.K. Norskov, Phys. Rev. B 59, 15990 (1999).

[47] A.U. Nilekar, A.V. Ruban, M. Mavrikakis, Surf. Sci. 603, 91 (2009).

[48] L.L. Wang and D.D. Johnson, J. Am. Chem. Soc. 131, 14023 (2009).

[49] Pearson's Handbook of Crystallographic Data for Intermetallic Phases (American Society for Metals, Cleveland, 1985). 
[50] L. Vitos, A.V. Ruban, H.L. Skriver and J. Kollar, Surf. Sci. 411, 186, (1998).

[51] W. R. Tyson and W. A. Miller, Surf. Sci. 62, 267 (1977).

[52] F.R. de Boer, R. Boom, W.C.M. Mattens, A.R. Miedema and A.K. Niessen, Cohesion in Metals, (NorthHolland, Amsterdam, 1988).

[53] G. Wang, M.A. Van Hove, P.N. Ross, M. I. Baskes, J. Chem. Phys. 122, 024706 (2005). 
Tables

Table 1

Calculated segregation energies (in eV) for an $\mathrm{Au}$ impurity in the three low-index $\mathrm{Cu}$ extended surfaces.

\begin{tabular}{llllll}
\hline & Surfaces & To layer & MEAM & DFT-GGA & DFT-LDA \\
\hline Au impurity in & $\mathrm{Cu}(111)$ & 1 st & -0.807 & -0.579 & $-0.29^{\mathrm{a}}$ \\
& $\mathrm{Cu}(100)$ & 1 st & -0.844 & -0.494 & $-0.18^{\mathrm{b}}$ \\
& $\mathrm{Cu}(110)$ & 1 st & -0.747 & -0.490 & \\
\hline
\end{tabular}

${ }^{\mathrm{a}}$ Reference [46], ${ }^{\mathrm{b}}$ Reference [47]. 
Table 2

Calculated segregation energies (in eV) for an $\mathrm{Au}$ atom in the three low-index $\mathrm{Cu}_{3} \mathrm{Au}$ extended surfaces. The energies correspond to the configurations in Figure 1.

\begin{tabular}{|c|c|c|c|c|}
\hline \multirow[t]{2}{*}{ Surfaces } & Initial & Final & MEAM & DFT \\
\hline & Structure & \multicolumn{3}{|l|}{ Structure } \\
\hline \multirow[t]{3}{*}{ (111) } & A & B & -0.125 & -0.096 \\
\hline & A & $\mathrm{C}$ & +0.031 & +0.014 \\
\hline & A & $\mathrm{D}$ & +0.145 & +0.196 \\
\hline \multirow[t]{4}{*}{ (100) } & $\bar{E}$ & $\mathrm{~F}$ & +0.168 & +0.155 \\
\hline & $\mathrm{E}$ & G & +0.165 & +0.112 \\
\hline & $\mathrm{E}$ & $\mathrm{H}$ & -0.302 & -0.323 \\
\hline & $\mathrm{E}$ & I & -0.389 & -0.315 \\
\hline \multirow[t]{4}{*}{ (110) } & $\mathrm{J}$ & K & +0.033 & -0.117 \\
\hline & $\mathrm{J}$ & $\mathrm{L}$ & -0.019 & -0.159 \\
\hline & $\mathrm{J}$ & M & +0.018 & -0.105 \\
\hline & $\mathrm{J}$ & $\mathrm{N}$ & -0.071 & -0.168 \\
\hline
\end{tabular}


Table 3

Comparison of the calculated lattice constants of $\mathrm{Cu}_{3} \mathrm{Au}\left(\mathrm{L}_{2}\right), \mathrm{CuAu}\left(\mathrm{L1}_{0}\right)$, and $\mathrm{CuAu}_{3}\left(\mathrm{~L}_{2}\right)$ bulks using the developed MEAM potential and the DFT method.

\begin{tabular}{llll}
\hline Bulk & Lattice & MEAM & GGA-DFT \\
Structure & Parameter & $(\AA)$ & $(\AA)$ \\
\hline $\mathrm{Cu3Au}\left(\mathrm{L1}_{2}\right)$ & $a$ & 3.822 & 3.791 \\
$\mathrm{CuAu}\left(\mathrm{L1}_{0}\right)$ & $a$ & 3.851 & 4.101 \\
& $c$ & 3.920 & 3.604 \\
$\mathrm{CuAu3}\left(\mathrm{L}_{2}\right)$ & $a$ & 3.937 & 4.062 \\
\hline
\end{tabular}


Parameters of the MEAM potentials for the $\mathrm{Cu}-\mathrm{Au}$ system: The cohesive energy $E_{c}(\mathrm{eV})$, the equilibrium nearest-neighbor distance $r_{e}(\AA)$, the decaying exponential factor of the universal energy $\alpha$, the scaling factor of the embedding function $\mathrm{A}$, four decaying exponential factors of the atomic charge density $\beta^{(i)}$, four weighting factors of the atomic charge density $t^{(i)}$, and the scaling factor of the atomic charge density $\rho^{(0)}$. The detailed information can be seen in Ref. 41-43.

\begin{tabular}{|c|c|c|c|c|c|c|c|c|c|c|c|c|c|}
\hline & $E_{\mathrm{c}}$ & $r_{\mathrm{e}}$ & $\alpha$ & $A$ & $\beta^{(0)}$ & $\beta^{(1)}$ & $\beta^{(2)}$ & $\beta^{(3)}$ & $t^{(0)}$ & $t^{(1)}$ & $t^{(2)}$ & $t^{(3)}$ & $\rho^{(0)}$ \\
\hline$\overline{\mathrm{Cu}}$ & 3.540 & 2.560 & 5.110 & 1.070 & 3.634 & 2.200 & 6.000 & 2.200 & 1.000 & 4.910 & 2.490 & 2.950 & 1.000 \\
\hline $\mathrm{Au}$ & 3.930 & 2.878 & 6.341 & 1.040 & 5.450 & 2.200 & 6.000 & 2.200 & 1.000 & 3.150 & 1.510 & 2.600 & 1.425 \\
\hline $\mathrm{Cu}-\mathrm{Au}$ & 3.657 & 2.703 & 7.750 & ---- & ---- & ---- & ---- & ---- & ---- & ---- & ---- & ---- & ---- \\
\hline
\end{tabular}


Table 5

Parameters of the MEAM potentials for the $\mathrm{Cu}-\mathrm{Au}$ system: Angular screening factors of the atomic charge density in $\mathrm{Cu}-\mathrm{Au}$ alloys.

\begin{tabular}{lllllll}
\hline & $\mathrm{Cu}-\mathrm{Cu}-\mathrm{Cu}$ & $\mathrm{Cu}-\mathrm{Au}-\mathrm{Cu}$ & $\mathrm{Au}-\mathrm{Cu}-\mathrm{Cu}$ & $\mathrm{Au}-\mathrm{Au}-\mathrm{Cu}$ & $\mathrm{Au}-\mathrm{Cu}-\mathrm{Au}$ & $\mathrm{Au}-\mathrm{Au}-\mathrm{Au}$ \\
\hline$C_{\max }$ & 2.8000 & 2.5833 & 2.5833 & 3.2500 & 3.5833 & 2.8000 \\
$C_{\min }$ & 0.8000 & 0.8333 & 1.0833 & 1.4167 & 1.9167 & 2.0000 \\
\hline
\end{tabular}


Table 6

Calculated surface energies of pure $\mathrm{Cu}(\mathrm{fcc})$ and pure $\mathrm{Au}$ (fcc) crystals using our developed MEAM potentials. For comparison, we also included the DFT calculation results and experimental data from the literature. In our calculations, $\mathrm{Cu}$ and $\mathrm{Au}$ have lattice constants of $\mathrm{a}=3.62 \AA$ and $\mathrm{a}=4.07 \AA$, respectively.

\begin{tabular}{lllll}
\hline & & MEAM & DFT $^{\mathrm{a}}$ & $\begin{array}{l}\text { Experiment } \\
\left(\mathrm{mJ} \mathrm{m}^{-2}\right)\end{array}$ \\
\hline $\mathrm{Cu}$ & $(111)$ & 1411 & 1952 & $1790^{\mathrm{b}}, 1825^{\mathrm{c}}$ \\
& $(100)$ & 1653 & 2166 & \\
& $(110)$ & 1614 & 2237 & \\
$\mathrm{Au}$ & $(111)$ & 866 & 1283 & $1506^{\mathrm{b}}, 1500^{\mathrm{c}}$ \\
& $(100)$ & 1035 & 1627 & \\
& $(110)$ & 974 & 1700 &
\end{tabular}

${ }^{\mathrm{a}}$ Reference [50], ${ }^{\mathrm{b}}$ Reference [51], ${ }^{\mathrm{c}}$ Reference [52] 
Comparison of the Au concentration in the first two outer most layers of both our predicted relaxed and unrelaxed Au concentrations with experimental results. Ref A [16] (900 K), Ref B [17] (573 K), Ref C [20] (400 K and $660 \mathrm{~K}$, respectively), Ref D [19] (1000 K), Ref E [22,23] (890 K), Ref F [15] (990 K), Ref G [30] (924 K), Ref H [29] (700 K), Ref I [25] (879 K), Ref J [27] (873 K), Ref K [29] (1000K)

\begin{tabular}{|c|c|c|c|c|c|c|}
\hline Surface & $\begin{array}{l}\text { Bulk } \\
\text { Au at. \% }\end{array}$ & Layer & $\begin{array}{l}\mathrm{Au} \text { at. \% } \\
\text { (unrelaxed) }\end{array}$ & $\begin{array}{l}\text { Au at. \% } \\
\text { (relaxed) }\end{array}$ & $\begin{array}{l}\text { Experiment } \\
\text { Au at. \% }\end{array}$ & $\begin{array}{l}\text { Theoretical } \\
\text { Au at. \% }\end{array}$ \\
\hline \multirow[t]{2}{*}{ (111) } & 20 & 1 & 40.2 & 51.4 & $40^{\mathrm{A}}, 51^{\mathrm{B}}$ & $\sim 35^{\mathrm{G}}, \sim 55^{\mathrm{H}}$ \\
\hline & & 2 & 14.3 & 13.9 & $15^{\mathrm{A}}, 24^{\mathrm{B}}$ & $\sim 20^{\mathrm{H}}$ \\
\hline \multirow[t]{2}{*}{ (100) } & 25 & 1 & 53.6 & 59.7 & $41^{\mathrm{D}}, 45^{\mathrm{E}}, 36^{\mathrm{F}}$ & $\sim 55^{\mathrm{G}}, 44^{\mathrm{I}}, \sim 45^{\mathrm{J}}, \sim 50^{\mathrm{K}}$ \\
\hline & & 2 & 14.6 & 12.8 & $18^{\mathrm{D}}, 14^{\mathrm{E}}, 31^{\mathrm{F}}$ & $\sim 10^{\mathrm{K}}$ \\
\hline \multirow[t]{2}{*}{ (110) } & 25 & 1 & 59.8 & 54.2 & $45^{\mathrm{C}}, 35^{\mathrm{C}}$ & $\sim 50^{\mathrm{G}}$ \\
\hline & & 2 & 41.8 & 39.8 & $20^{\mathrm{C}}, 35^{\mathrm{C}}$ & \\
\hline
\end{tabular}


Figures

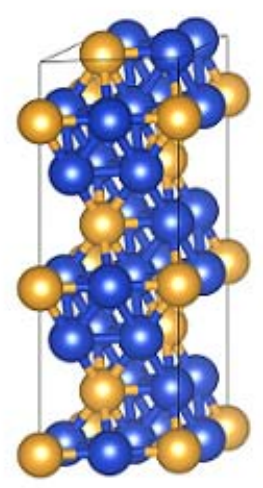

A

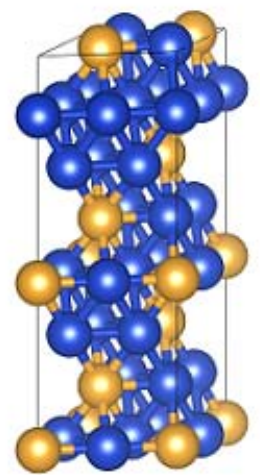

B

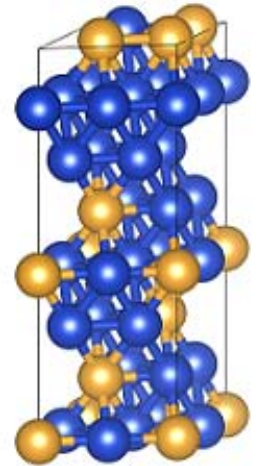

C

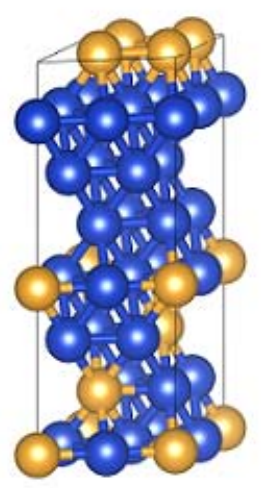

D

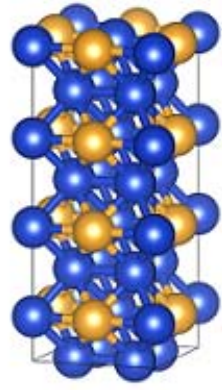

E

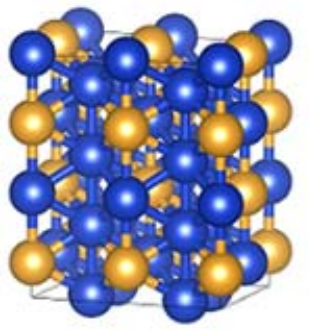

J

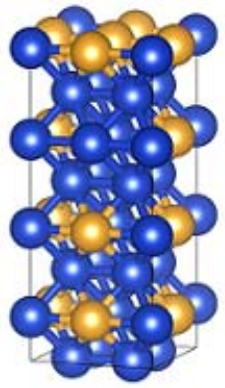

F

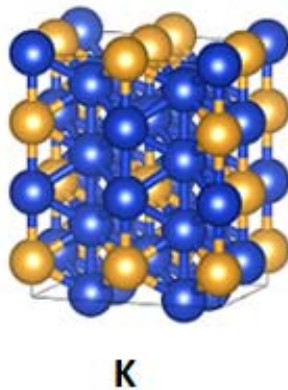

K

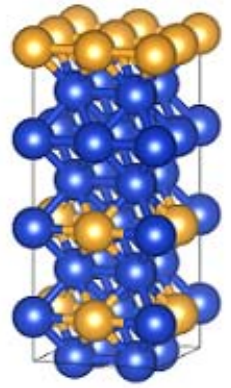

G

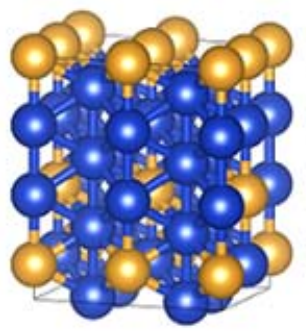

L

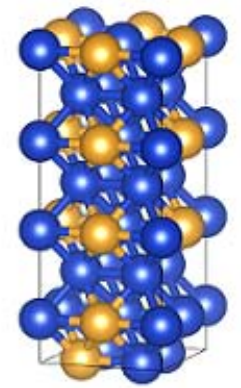

H

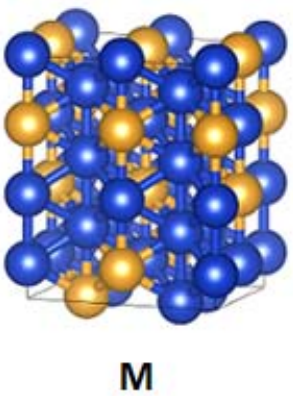

M

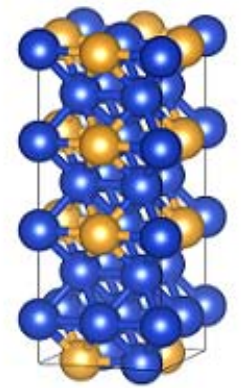

I

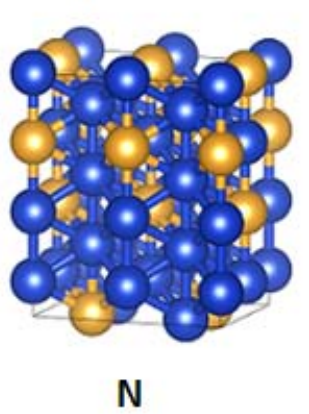

Fig. 1: The relaxed atomistic structures of various terminations (top layer with different compositions) of the (111) [panels A, B, C, and D], (100) [panels E, F, G, H, and I], and (110) [panels J, K, L, M, and N] of the ordered $\mathrm{Cu}_{3} \mathrm{Au}$ crystal. In the figure, the blue balls represent $\mathrm{Cu}$ atoms, while the gold balls represent $\mathrm{Au}$ atoms. 


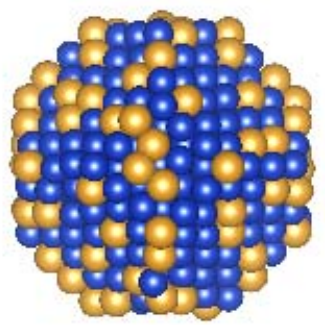

(a)

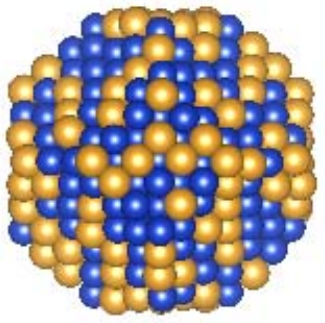

(c)

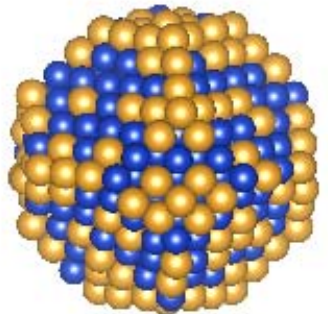

(e)

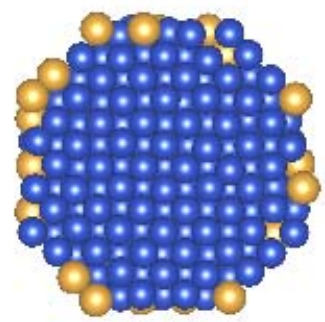

(b)

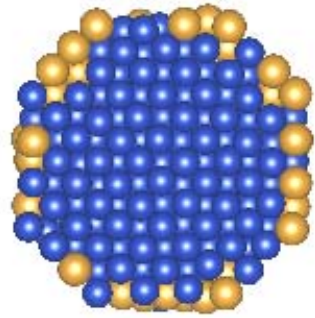

(d)

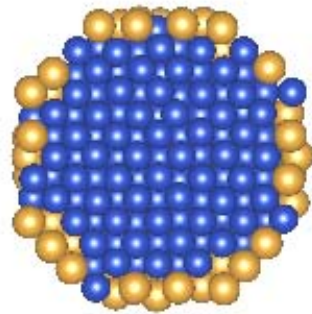

(f)

Fig. 2: Snapshots of the equilibrium cubo-octohedral nanoparticles of $\mathrm{Cu}-\mathrm{Au}$ alloys from the $\mathrm{MC}$ simulations at $T=500 \mathrm{~K}$, (a), (c) and (e) show external views of $\mathrm{Cu}_{85} \mathrm{Au}_{15}, \mathrm{Cu}_{80} \mathrm{Au}_{20}$ and $\mathrm{Cu}_{75} \mathrm{Au}_{25}$ nanoparticles, respectively. (b), (d) and (f) show [001] cross-sectional views of the same nanoparticles, respectively 


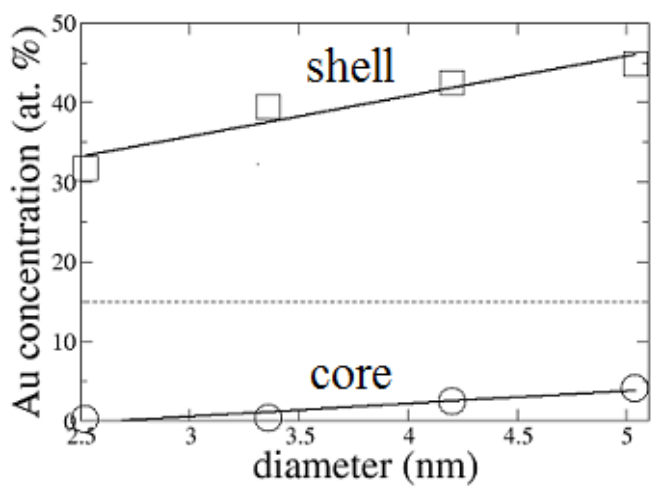

(a)

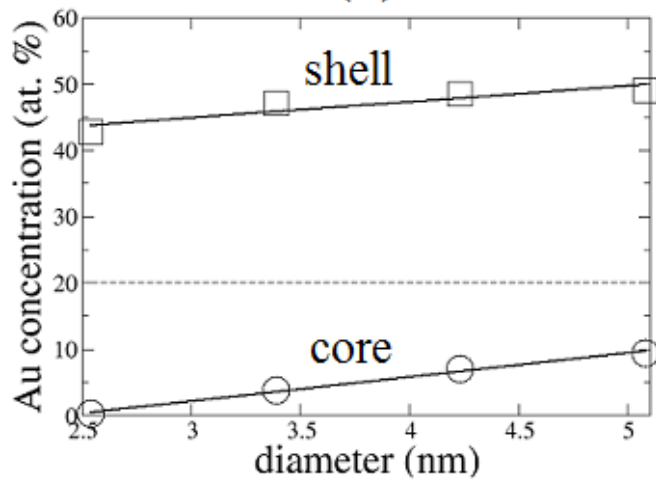

(c)

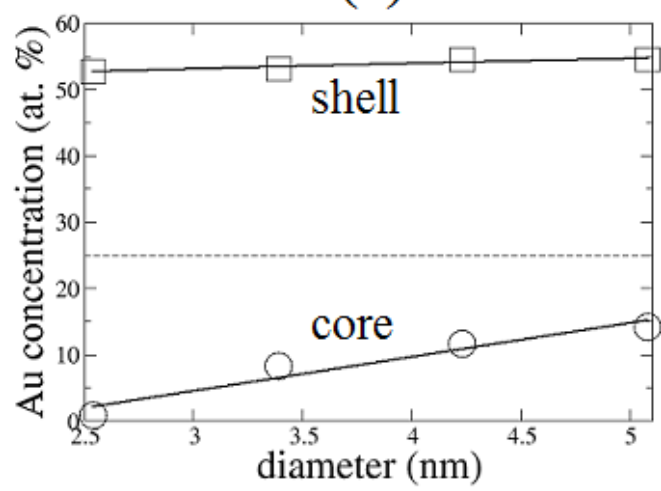

(e)

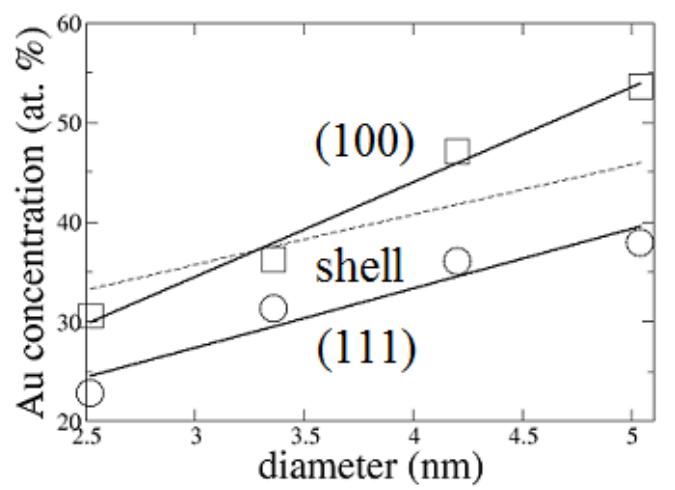

(b)

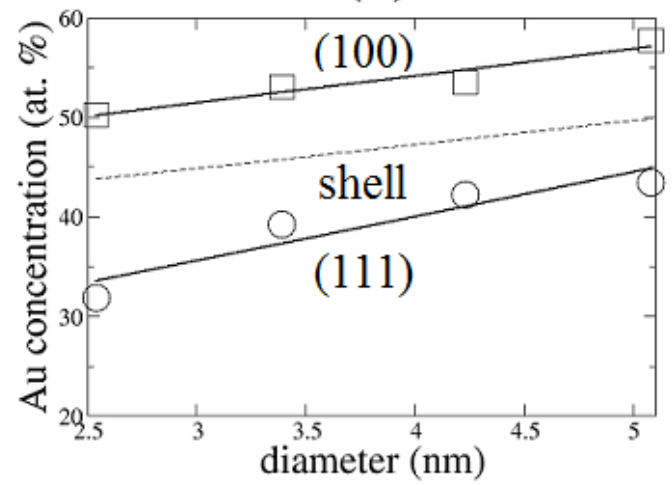

(d)

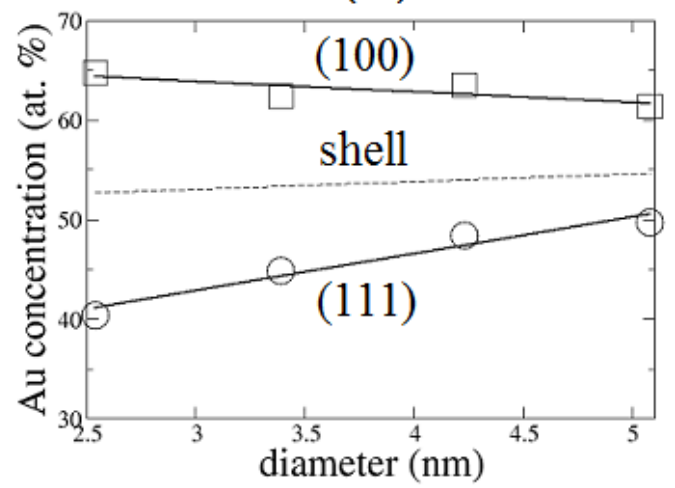

(f)

Fig. 3: Predicted equilibrium surface $\mathrm{Au}$ concentrations in the cubo-octohedral nanoparticles of (a, b) $\mathrm{Cu}_{85} \mathrm{Au}_{15}$. (c, d) $\mathrm{Cu}_{80} \mathrm{Au}_{20}$ and (e, f) $\mathrm{Cu}_{75} \mathrm{Au}_{25}$ alloys using the $\mathrm{MC}$ simulation method at temperature of $500 \mathrm{~K}$. In (a), (c) and (e), the squares represent the Au concentration in the shell (outermost surface layer) and the circles represent the $\mathrm{Au}$ concentration in the core (interior region beneath the shell), which the dashed line represents the overall Au concentration of the nanoparticles.. In (b), (d) and (f), the squares represent the Au concentration at the (100) facets of the shell and the circles represent the Au concentration at the (111) facets in the shell, and the dashed line indicates the equilibrium Au concentration in the shell of the nanoparticles. 


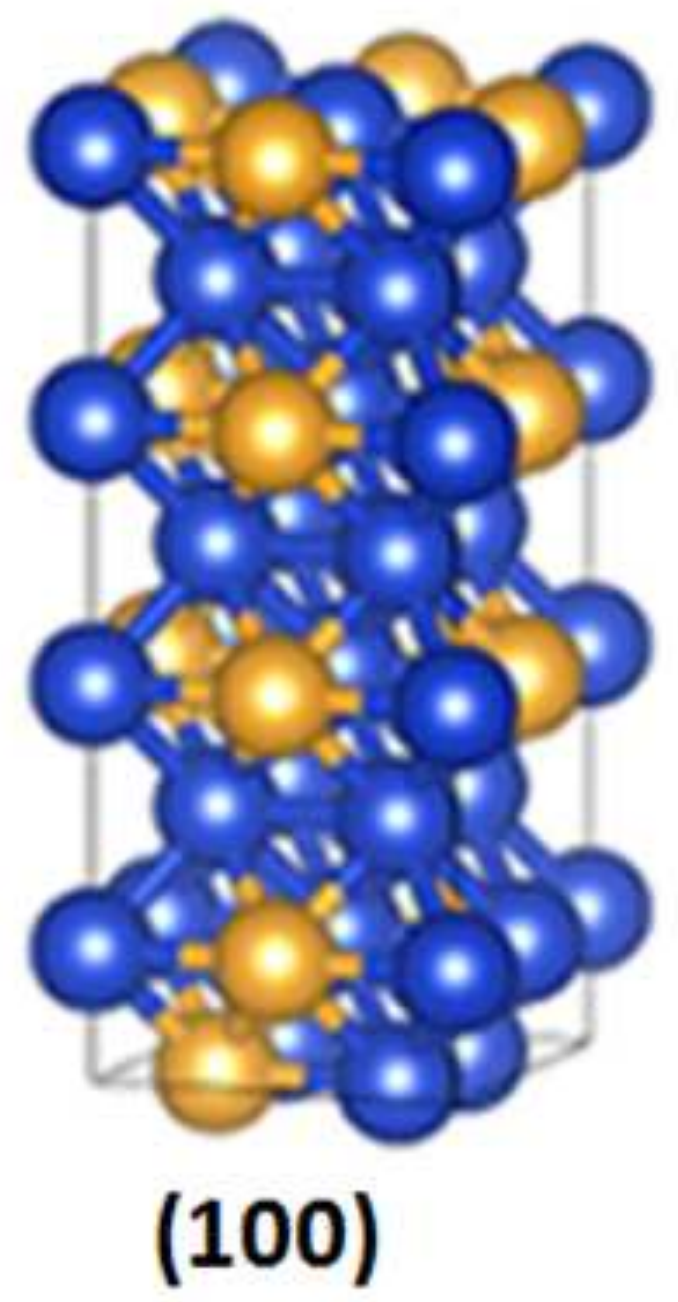

(100)

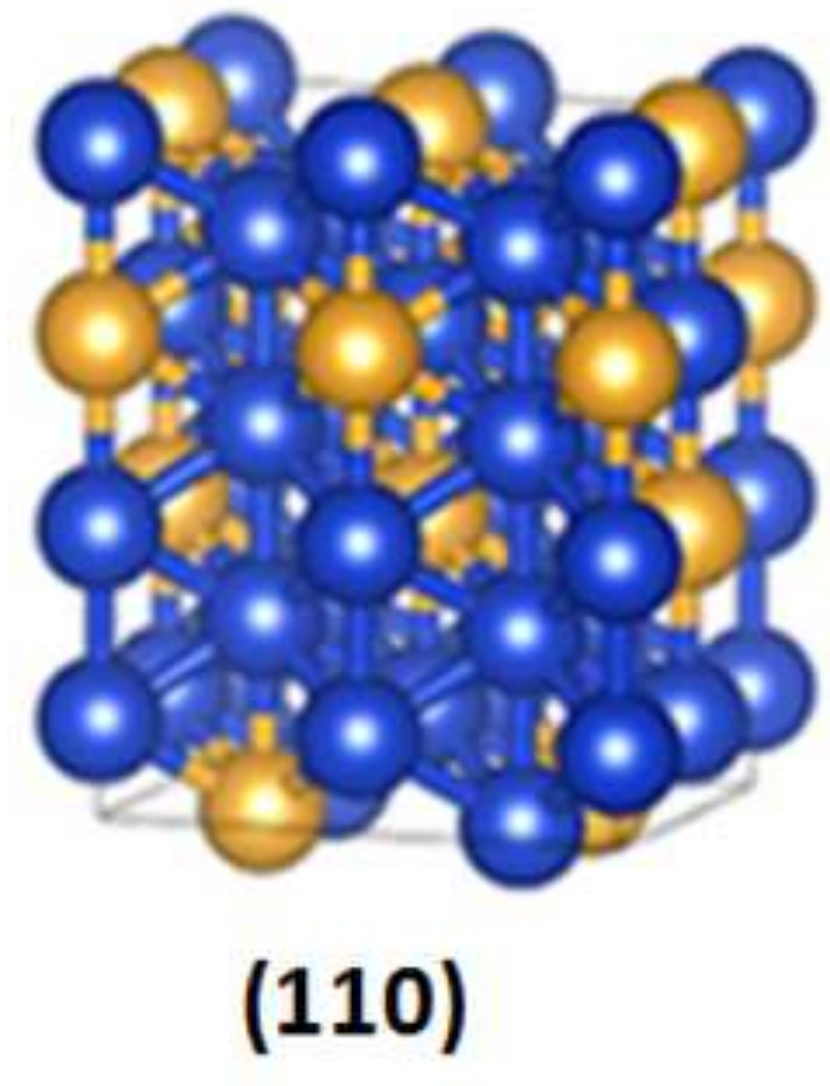

(110)

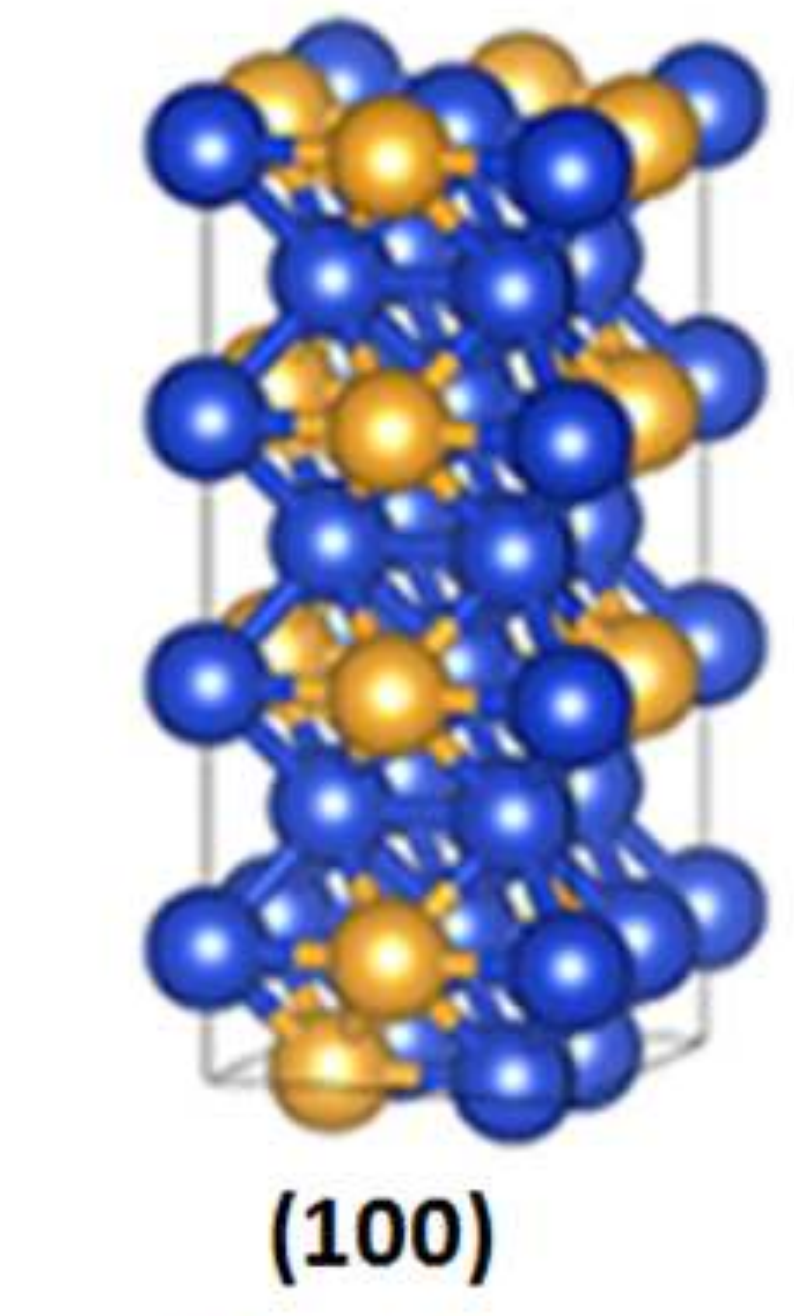

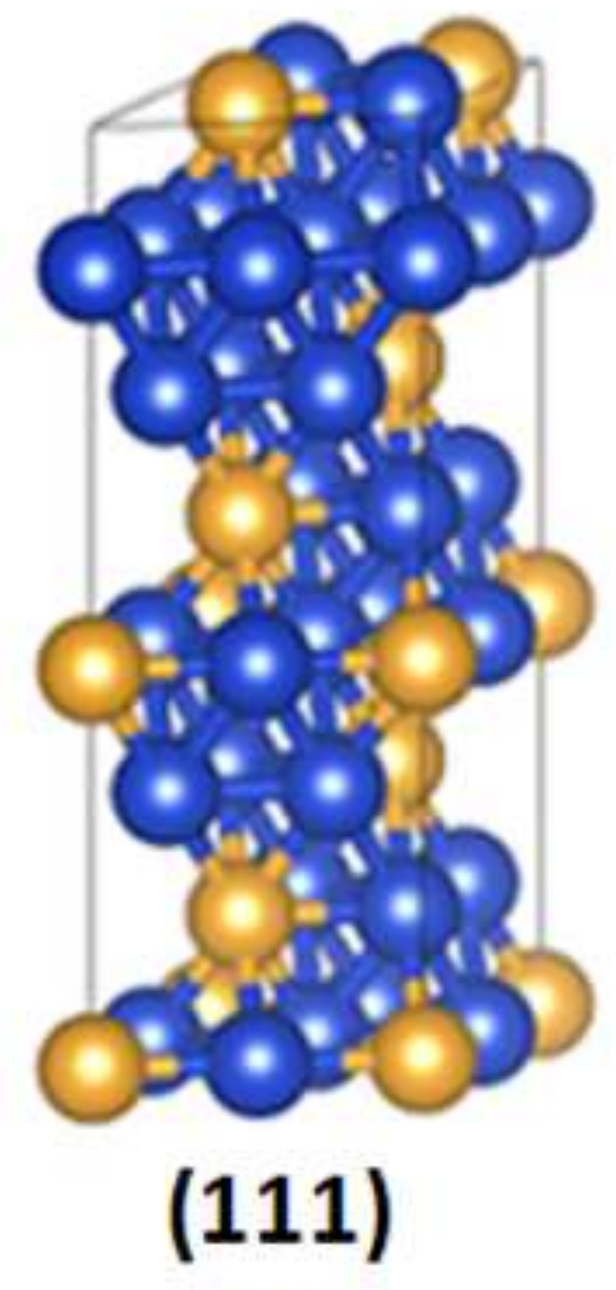

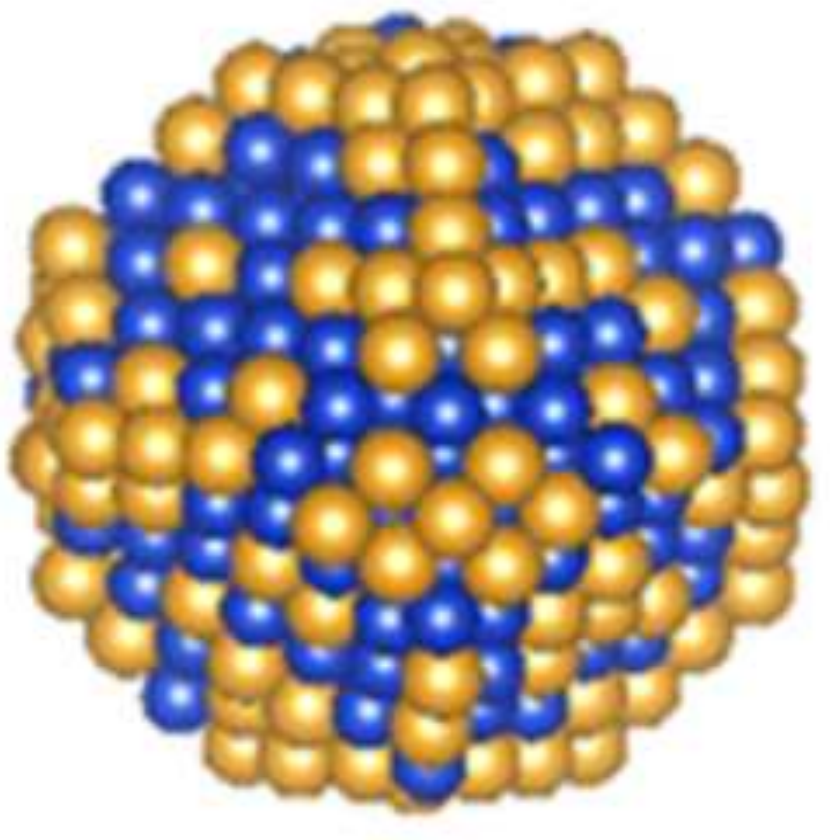

$\mathrm{Cu}-\mathrm{Au}$

nanoparticle

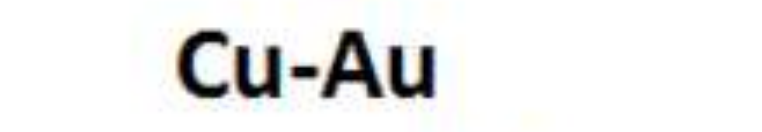

(111)
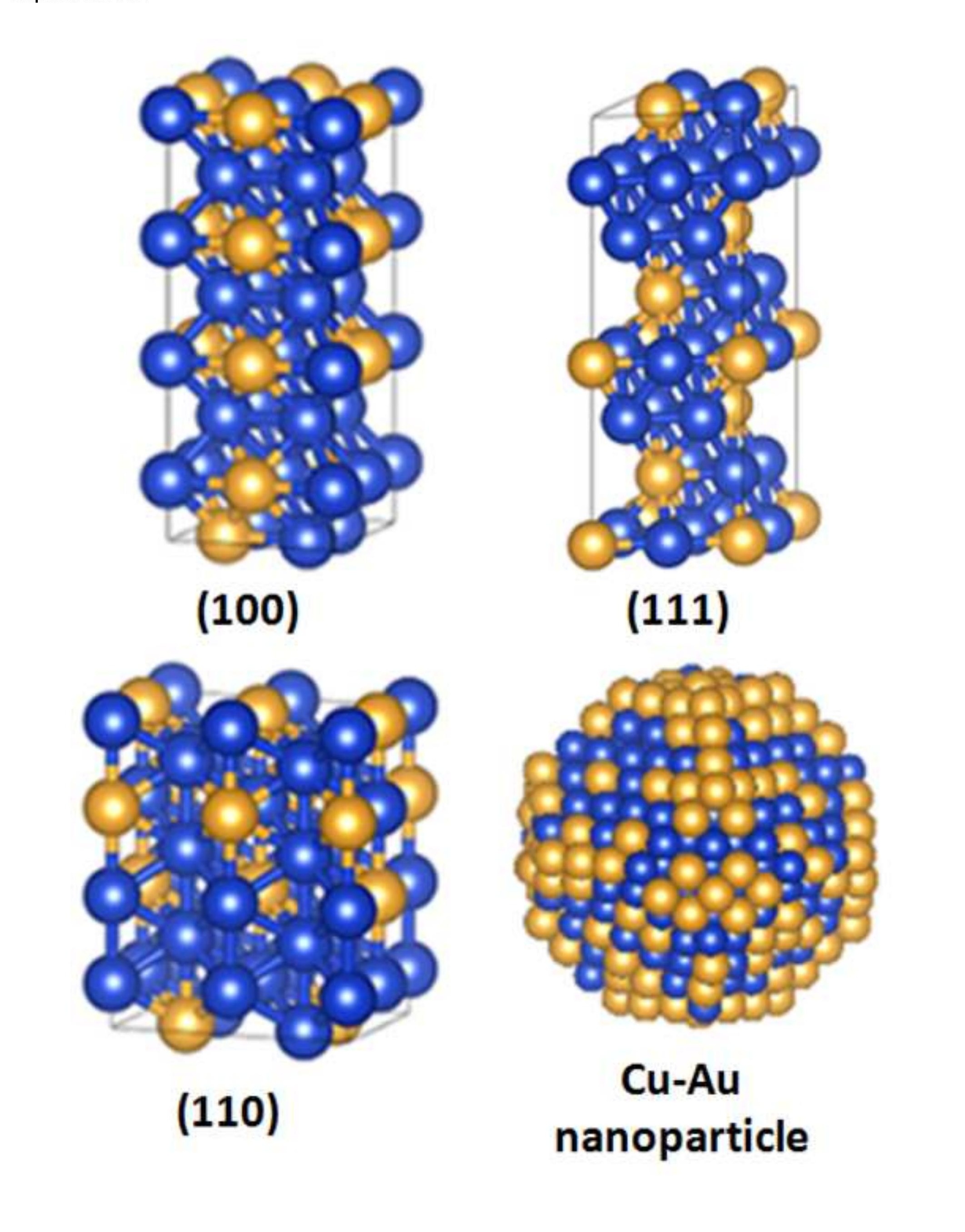